\title{
PSICOLOGIA E POLÍCIA MILITAR: UM ESTUDO SOBRE A MENTE POLICIAL NO ESTADO DO ACRE
}

\section{ARTIGO ORIGINAL}

PINTO, Édila Mazília de Aguiar ${ }^{1}$, LIMA, Neurilan Marcos de ${ }^{2}$

PINTO, Édila Mazília de Aguiar. LIMA, Neurilan Marcos de. Psicologia e polícia militar: um estudo sobre a mente policial no estado do Acre. Revista Científica Multidisciplinar Núcleo do Conhecimento. Ano 06, Ed. 08, Vol. 02, pp. 50-80. Agosto de 2021. ISSN: 2448-0959, Link de acesso: https://www.nucleodoconhecimento.com.br/psicologia/psicologia-e-policia, $\quad$ DOI: 10.32749/nucleodoconhecimento.com.br/psicologia/psicologia-e-policia

Quem combate monstruosidades deve cuidar para que não se torne um monstro. E se você olhar longamente para um abismo, o abismo também olha para dentro de você. (NIETZSCHE)

\section{RESUMO}

A atividade policial é permeada por situações de perigo, o que acaba definindo como um trabalho extremamente estressante, o que pode influir nos aspectos psicológicos e emocionais dos agentes de segurança. Nessa perspectiva, este estudo teve como finalidade explorar a percepção dos Policiais Militares na Cidade de Rio Branco e Interior do Estado do Acre, sendo atingido quatro Batalhões, e alcançando 212 Policiais Militares. $O$ objetivo foi investigar as principais inquietações que afligem na mente desses profissionais e suas possíveis consequências em sua vida e no trabalho. O estudo caracterizou-se como quali-quantitativo, através da aplicação de questionário individual em uma escala de 20 questões, abordando assuntos relativos ao objetivo proposto. Os resultados gerais demonstraram que a maioria dos Militares

\footnotetext{
${ }^{1}$ Especialização em Psicologia Jurídica, Graduação em Psicologia.

2 Pós em Direito constitucional; Mestrando em ciências da educação.
}

RC: 93449

Disponível em: https://www.nucleodoconhecimento.com.br/psicologia/psicologia-e- 
$(52,35 \%)$ consideram que "sempre" a realização de horas extras é prejudicial para a saúde mental; 49,05\%, apontaram que "ás vezes" se sentiam emocionalmente cansados após um dia de trabalho; $63,20 \%$, indicaram que "sempre" consideram o acompanhamento psicológico importante para a profissão; $52,35 \%$, "às vezes" ou "sempre" consideram o trabalho estressante e 33,96\%, "nunca" se sentem valorizados enquanto Policiais Militares. Verifica-se que é necessárias intervenções que visem a promoção da saúde mental dos profissionais, a fim de efetivar a minimização de inquietações e sofrimentos produzidos principalmente pela atividade policial.

Palavras-chave: Psicologia, Polícia Militar, Saúde mental.

\section{INTRODUÇÃO}

Compreende-se que o trabalho policial é considerado como uma das profissões que mais ocasionam estresse e desgaste, conforme aponta a literatura em geral. Se tratando sobre a Polícia Militar, essa possuí grande impacto na sociedade, o que motiva ser constantemente julgada por ela, já que sua principal incumbência é servir e proteger os cidadãos, trabalhando diretamente na rua, e em contato direto com a sociedade. (OLIVEIRA; FAIMAN, 2019)

Evidentemente, como aponta Oliveira e Faiman (2019), a percepção de como o indivíduo é reconhecido na sociedade como representante de sua profissão pode ocasionar impactos no seu funcionamento emocional, principalmente quando sua atividade laboral contribui para suas aptidões psíquicas, já que a descarga de energia (excitação) ocasiona bem-estar e proporciona equilibro psíquico. Em contrapartida, existem situações que sobrecarregam o indivíduo em seu aspecto psíquico por demostrarem um aumento de tensão, questão bem presente na rotina policial.

RC: 93449

Disponível em: https://www.nucleodoconhecimento.com.br/psicologia/psicologia-epolicia 
Assim, verifica-se que o policial está exposto a constante estresse, o que contribui para gerar sofrimento psíquico o que pode corroborar para a diminuição de sua eficácia profissional. Nesse sentido, o sofrimento estando relacionado ao processo laboral se torna necessário ser compreendido as causas para que possam existir mudanças e contingências favoráveis ao processo de trabalho. Frente ao exposto, verifica-se que o acompanhamento psicológico é de fundamental relevância aos Policiais Militares que lidam diariamente com a violência, dor e situações de perigo. (OLIVEIRA; SANTOS, 2010)

Partindo do que foi exposto, neste trabalho, buscou-se a reflexão sobre a percepção que os Policiais Miliares possuem acerca de sua própria saúde mental, através de um levantamento de dados de cunho quali-quantitativo, onde foram analisados sobre opiniões que influem nos valores e formas de conduta, e que podem estar associados pelo trabalho policial. Os dados aqui apresentados, serão retratados a partir de um contexto apontado pelo Policial Militar na sua atividade profissional, cujo objetivo é salientar como a atividade laboral pode afetar a saúde mental dos mesmos.

A busca de compreender a realidade policial e como essa atividade pode influenciar nos aspectos psicológicos, se tornou o ponto de partida para a elaboração do presente estudo, verificando que especificamente no Estado do Acre, nunca houve um levantamento sobre os Policiais Militares acerca de sua saúde mental, e como a atividade policial pode prejudicar o emocional desses trabalhadores.

Nesse sentido, é necessário compreender como o trabalho pode aferir na vida dos policiais, e assim, seja compreendido a necessidade de elaboração de estratégias preventivas e/ou Políticas Públicas com um plano de ações para proporcionar uma melhora na qualidade de vida dos Policiais Militares da região, considerando que com a melhora na saúde mental, consecutivamente irão ofertar um labor com maior eficiência para à sociedade que necessita dos seus serviços.

RC: 93449

Disponível em: https://www.nucleodoconhecimento.com.br/psicologia/psicologia-epolicia 


\section{REVISÃO DE LITERATURA}

É apontado que o trabalho do Policial Militar se constitui como uma das categorias de profissão com maior risco de vida e estresse. É uma profissão que possuí grande visibilidade na sociedade, e por isso, também é julgada por ela, tendo em vista que a polícia tem o dever de servir e proteger o cidadão, atuando diretamente nas ruas, em contato direto com a sociedade. Diversos conceitos sobre a atuação do Policial Militar são formados, e ainda se faz necessário ser mais investigada para compreender sobre seu funcionamento (FAIMAN; OLIVEIRA, 2019).

Santos e Oliveira (2010, p.225) retratam sobre a atividade dos Policiais Militares:

Os policiais militares se referem aos profissionais que desempenham atividade no âmbito federal ou no estadual, recebendo por este serviço um subsídio. Para um bom exercício profissional, o militar deve saber lidar com o conjunto de tarefas a ele conferidas e não se abster de cumprir suas obrigações, mesmo que isso implique em algum dilema ideológico pessoal.

Em face dessa contingência, a profissão do Policial Militar é representada com a atuação diretamente ao combate da criminalidade, a favor de toda a sociedade e assim, proteger os cidadãos, atuando diretamente com as pessoas e as mais diversas situações conflituosas e inusitadas em sua rotina de trabalho.

Lustosa; Gonçalves (2017), discorrem que quando o indivíduo ingressa na Polícia Militar, é submetido a mudanças e adaptações para se tornar um policial. Considerase que existe uma exigência de padrão discursiva e escrita na cultura que direciona o sujeito a seguir traços próprios da natureza militar. Isso faz com que o grau de exigência aumente ainda mais frente aos resultados esperados do seu trabalho, e que pode não fazer bem para o indivíduo. Essas premissas apontam ao que Oliveira e Santos (2010, p. 229) discorrem:

Um dos agravantes do estresse no trabalho do policial pode estar associado à limitação que a sociedade submete pessoas quanto às

RC: 93449

Disponível em: https://www.nucleodoconhecimento.com.br/psicologia/psicologia-e- 
manifestações de suas angústias, frustrações e emoções. Esse fato fica ainda mais grave no caso do policial, pois, se não há espaço para que tais manifestações sejam reveladas e trabalhadas, então, possivelmente, esses sintomas podem ser prejudiciais diante de uma situação que envolve risco.

Em conformidade com os autores, na corporação militar acaba não havendo espaço para reflexões acerca dos sentimentos e emoções, o que pode implicar em desordem psíquica pelo policial acabar não revelando o que lhe aflige.

Spuldaro e Nesi (2013, p.18) apontam que: "os Policiais estão entre as profissões que mais sofrem de estresse. De fato, estão expostos a perigo, agressões e situações de problemas humanos de muito conflito e tensão." Para melhor compreender sobre estresse, Lipp (2010, p.02) corrobora que:

Compreende-se que o estresse é um desgaste do organismo influído pelas alterações psicofisiológicas quando o indivíduo se denota a enfrentar situação que cause irritação, medo, excite ou confunda, ou até que a faça imensamente feliz. Assim, se trata de uma reação do organismo que acontece quando é necessário lidar com situações que precisam de grande esforço para ser superadas. (LIPP, 2010, p. 02)

Conforme mencionado, não se considera o estresse como uma patologia em si, entretanto, pode se tornar um aspecto desencadeante para o desenvolvimento de transtornos mentais caso o sujeito se submeta a ações rotineiras de agentes estressores, podendo a chegar ao denominado estresse crônico.

Se tratando de Policiais Militares, o nível de estresse mostra-se como superior se avaliado a outras profissões, não se limitando apenas as atividades exercidas, mas também pela sobrecarga de trabalho e pelas relações internas com a corporação, já que são fundamentadas em disciplina e hierarquia militar. (SPULDARO; NESI, 2013)

Segundo Souza, et al. (2012, p. 1297): "Tais características estruturantes tornam a instituição resistente a mudanças e repercutem na saúde física e mental dos servidores. " Além disso, ainda são existentes outros fatores geradores de estresse,

RC: 93449

Disponível em: https://www.nucleodoconhecimento.com.br/psicologia/psicologia-e- 
como as situações conflituosas de policiais e o Sistema de Justiça, e o público quem atendem.

Os policiais apresentam influências de vários aspectos negativos que influenciam o estresse extremo, conforme apontam os autores:

O cansaço físico e a falta de equilíbrio emocional podem levar esses profissionais a assumirem atitudes irracionais durantes crises e situações caóticas. Assim, tais atitudes podem levar à falta de eficácia no desempenho do exercício profissional, expondo os policiais e a população em geral a perigos em potencial. (SANTOS; OLIVEIRA, 2010, p.227)

A partir do relato apresentado, verifica-se que a profissão militar exige do policial muitos sacrifícios, incluindo a sua própria vida em benefício do outro. A morte é considerada uma realidade em sua profissão, podendo se apresentar com a morte das vítimas, criminosos e dos próprios colegas de trabalho.

$\mathrm{Na}$ atividade diária, o Policial Militar lida com alta taxa de adrenalina, estando sempre em estado de alerta para agir. Para Santana; Sabino (2020, p.05): "À medida que aumenta o nível de tensão, aumenta também o nível de vigilância e de expectativa, passando a estar pronto para agir a qualquer instante de maneira enérgica. "Dessa forma, o policial vive em uma pressão constante, o que irá influenciar no seu funcionamento normal de pensar e agir, podendo apresentar dificuldades em direcionar suas prioridades, apresentando sensação de hesitação, raciocínio confuso, entre outros, que passam a fazer parte da sua rotina.

Aponta-se que o exercício profissional do Policial Militar pode influenciar outros setores de sua vida, já que a rigidez militar e as características do seu ofício pode influenciar seu modo de ser e agir, o que irá refletir em sua vida pessoal. Santana e Sabino (2020, p.05), sobre essa realidade afirmam que:

O policial não é o único que sofre as consequências do estresse provocado pelo seu trabalho. No ambiente familiar, o membro da corporação militar tende a desligar as emoções em relação a sua

RC: 93449

Disponível em: https://www.nucleodoconhecimento.com.br/psicologia/psicologia-e- 
família e é levado a um processo de afastamento e procura de relações fora de casa. $\mathrm{Na}$ rua, alguns podem extravasar suas frustrações sobre os cidadãos tornando-se arbitrários, agressivos e grosseiros. (SANTANA; SABINO, 2020, p.05)

Dessa maneira, o rigor disciplinar e o efeito da exposição à violência podem repercutir para outras áreas da vida do policial militar, e ser incorporado no seu funcionamento pessoal, podendo influenciar no seu relacionamento familiar e no seu meio social, o que faz refletir sobre o impacto que o trabalho policial pode ocasionar. (OLIVEIRA, FAIMAN, 2019)

Santana e Sabino (2020), retratam que alguns estudos afirmam que o estresse e outras queixas emocionais como suicídio, divórcio e alcoolismo estão bem presentes no meio Policial. Outra pesquisa realizada afirmou que: "entre 149 profissões estudadas, apenas 10 excediam a Policial em doenças do coração, diabetes, insônia, suicídio e outras relacionadas com o estresse" (SANTANA; SABINO, 2020, p. 05).

A respeito da inserção do psicólogo na Polícia Militar destaca-se que é um fato recente, considerando que os primeiros profissionais foram inseridos na PMMG no ano de 1987, ressaltando que por um longo período os psicólogos atuaram apenas com processos de recrutamento e seleção, para posteriormente, trabalhar com a formação e o treinamento. A partir da entrada de novos psicólogos em 1994, 1995 e 2003 e 2007, ocorreu o aumento dos serviços de atendimento de Psicologia, havendo psicólogos nos mais diversos Batalhões da PMMG, todavia, esse aumento ainda foi considerado insuficiente se comparado ao crescimento do efetivo de policiais e de novos batalhões, ainda mais que, muitos psicólogos estavam em processo de aposentadoria (LUSTOSA; GONÇALVES, 2017).

Os autores Lustosa e Gonçalves (2017, p. 37) assinalam que:

Acredita-se que a estimulação, no ambiente organizacional, de um paradigma que favoreça a inserção da Psicologia com mais efetividade seria benéfica à minimização do sofrimento mental e,

RC: 93449

Disponível em: https://www.nucleodoconhecimento.com.br/psicologia/psicologia-e- 
consequentemente, a melhoria da qualidade de vida, especialmente do militar da ativa, que é tratado aqui como um público privilegiado.

Conforme corrobora os autores, para a quebra de resistência dos paradigmas sobre a Psicologia no campo militar, é necessário ser elaborado estratégias para inverter o lugar do policial acerca de sua percepção, e reconhecê-lo como sujeito, respeitando a subjetividade e singularidade, para depois, ser instituído no lugar de policial.

Brasil (2013) considera que no momento de tensão, o preparo psicológico é fundamental para o policial ter o preparo de tomar decisões rápidas. Assim, ele poderá compreender a natureza de sua função, com preparo e conhecimento dos limites que poderá exercer. Desse modo, em situações conflitantes, o militar saberá tomar decisões de acordo com o Estado democrático, agindo de maneira coerente, conforme solicitado a natureza de sua atuação profissional.

Lustosa; Gonçalves (2017, p. 38) apontam que: "A Psicologia tem o papel de mediar os conflitos e as perturbações que surgem desse quadro, configurado por demandas rígidas sobre o policial, justamente nos momentos em que esse sujeito depara na prática com suas fragilidades e impossibilidades". Nesse sentido, a atuação do psicólogo se baseará na prevenção e nos agravos psíquicos, buscando melhorar a qualidade de vida do profissional.

\section{MÉTODO}

Este trabalho se trata de um estudo quali-quantitativo, que de acordo com o Dicionário Informal (2021, p.01): "é usada para obter uma compreensão e explicação mais ampla do tema estudado, permitindo que o pesquisador consiga um cruzamento de conclusões, tendo mais confiança nos seus dados." Nesse sentido, foi utilizado o método para averiguar opiniões concretas entre os entrevistados, buscando analisar de forma precisa as hipóteses levantadas, para comparar as respostas fornecidas, levando em consideração que a percepção dos próprios Policiais Militares acerca da sua saúde mental é pouco explorada.

RC: 93449

Disponível em: https://www.nucleodoconhecimento.com.br/psicologia/psicologia-epolicia 
Salienta-se que o presente estudo teve como princípio base o trabalho desenvolvido por Oliveira e Santos (2010), a partir da análise desenvolvida sobre a percepção da saúde mental em Policiais Militares da força tática e de rua na Cidade de São Paulo.

\subsection{PARTICIPANTES}

Participaram no total 212 Policiais Militares lotados em (04) quatro Batalhões na Cidade de Rio Branco, e no interior do Estado do Acre, situado no Munícipio de Senador Guiomard. A pesquisa atingiu policiais da graduação de Oficiais e Praças. Os participantes foram de ambos os sexos, e que estavam em atividade. Policiais que estavam afastados momentaneamente das atividades ou em período de folga no dia da execução da pesquisa não participaram do estudo.

No $1^{\circ}$ Batalhão, houve a participação de 109 Policiais, sendo que o gênero masculino representou $89,90 \%$ desse quantitativo, e o feminino $10,09 \%$. A idade dos participantes foram entre 23 a 49 anos. Acerca da escolaridade, a maioria dos Policiais Militares afirmaram ter o ensino superior completo representado por $59,63 \%$, seguido de $22,93 \%$ para o superior incompleto, $8,25 \%$, continham pósgraduação e 5,50\% o ensino médio completo.

No $2^{\circ}$ Batalhão foram alcançados 63 Policiais Militares. O gênero masculino representou $95,23 \%$ e o feminino $4,76 \%$. A idade dos participantes variou entre 21 a 50 anos. No que se refere a escolaridade, $52,38 \%$ dos militares afirmaram ter 0 ensino superior completo, $25,39 \%$ superior incompleto, $14,28 \%$ pós-graduação e $4,76 \%$ o ensino médio completo.

No $3^{\circ}$ Batalhão participaram do estudo 20 policiais, representando $50 \%$ do efetivo. $O$ gênero masculino representou $100 \%$ no geral. $A$ idade dos participantes variou entre 24 a 55 anos. Sobre a escolaridade, a maioria dos policiais afirmaram ter o ensino superior completo $(60 \%)$, seguido de $25 \%$ para superior incompleto, $5 \%$ pósgraduação e $5 \%$ ensino médio completo.

RC: 93449

Disponível em: https://www.nucleodoconhecimento.com.br/psicologia/psicologia-epolicia 
No $4^{\circ}$ Batalhão, situado no Munícipio de Senador Guiomard, interior do Estado do Acre, 20 policiais participaram da pesquisa, representando $50 \%$ do efetivo. O gênero masculino foi predominante no estudo. A idade dos entrevistados foram entre 28 a 47 anos. No que se refere à escolaridade, observou-se que a maioria $(50 \%)$ apresentava o ensino superior completo, a outra parte (15\%) superior incompleto, $20 \%$ continham pós-graduação e $10 \%$ o ensino médio completo.

\subsection{INSTRUMENTOS}

O procedimento desenvolvido foi através da aplicação de questionário com 20 questões objetivas (fechadas) que foram respondidas anonimamente, em escala likert de 4 pontos, onde foram levantados a frequência do comportamento em: "raramente", "às vezes", "sempre" e "nunca", exceto para uma única questão que foi aplicada em forma dicotômica, de sim ou não. Em todas as questões os participantes tiveram que assinalar com um $X$ em apenas uma alternativa. $O$ questionário foi direcionado para os seguintes temas: cansaço emocional, estresse, ansiedade, insônia, satisfação profissional, acompanhamento psicológico e suicídio.

\subsection{PROCEDIMENTOS}

Os questionários foram aplicados presencialmente pela pesquisadora, em modelo impresso, de maneira individual, sendo garantido a confidencialidade das respostas do participante, e ocorrendo nas próprias dependências dos respectivos Batalhões, a fim de que pudesse ser acompanhado de perto o desenvolvimento da pesquisa. Os policiais que consentiram em participar do estudo, foram informados sobre a intenção da pesquisa, estando cientes que sua participação seria voluntária, além de ser especificado a necessidade de sua anuência através do termo de consentimento livre e esclarecido, ficando uma via em seu poder, e se desejasse, poderia interromper sua participação a qualquer momento, mesmo que já houvesse iniciado.

RC: 93449

Disponível em: https://www.nucleodoconhecimento.com.br/psicologia/psicologia-e- 
Salienta-se que o projeto de pesquisa foi avaliado e aprovado pelo Comitê de Ética em Pesquisa com Seres Humanos pela Universidade Federal do Estado do Acre, UFAC, pelo CAEE (Certificado de Apresentação de Apreciação Ética) de número: 40671820.8.0000.5010, e assim, destaca-se que foram obedecidos todos os critérios de procedimentos éticos, respaldados pelo Conselho Nacional de Saúde através da Resolução de 196/96.

\section{RESULTADOS}

Neste item serão apresentadas as respostas dos policiais entrevistados com os dados percentuais. Posteriormente serão analisados e discutidos cada questão pormenorizadamente.

Inicialmente foi questionado se o relacionamento familiar já havia sido afetado por influência da profissão. O resultado geral apontou que a maioria $(61,32 \%)$ dos policiais consideravam que "às vezes" já interferiu no convívio familiar.

Tabela 01 - Resultado das respostas sobre relacionamento familiar

\begin{tabular}{|l|l|l|l|l|l|}
\hline Questões & Grupo & Raramente & Às vezes & Sempre & Nunca \\
\hline $\begin{array}{l}\text { Você considera } \\
\text { que de algum }\end{array}$ & $\mathbf{1}^{\circ}$ BPM & $18,34 \%$ & $61,46 \%$ & $11 \%$ & $9,17 \%$ \\
$\begin{array}{l}\text { modo, seu } \\
\text { trabalho já } \\
\text { interferiu no seu }\end{array}$ & $\mathbf{2}^{\circ}$ BPM & $14,28 \%$ & $66,66 \%$ & $6,34 \%$ & $12,69 \%$ \\
$\begin{array}{l}\text { relacionamento } \\
\text { familiar? }\end{array}$ & $\mathbf{3}^{\circ}$ BPM & $20 \%$ & $50 \%$ & $20 \%$ & $10 \%$ \\
\hline & & 4 & 10 & 4 & 2 \\
\hline
\end{tabular}

RC: 93449

Disponível em: https://www.nucleodoconhecimento.com.br/psicologia/psicologia-e- 


\begin{tabular}{|c|c|c|c|c|c|}
\hline & $4^{\circ} \mathrm{BPM}$ & $\begin{array}{l}15 \% \\
3\end{array}$ & $\begin{array}{l}55 \% \\
11\end{array}$ & $\begin{array}{l}20 \% \\
4\end{array}$ & $\begin{array}{l}10 \% \\
2\end{array}$ \\
\hline Resultado Geral & & $\begin{array}{l}16,98 \% \\
36\end{array}$ & $\begin{array}{l}61,32 \% \\
130\end{array}$ & $\begin{array}{l}11,32 \% \\
24\end{array}$ & $\begin{array}{l}10,37 \% \\
22\end{array}$ \\
\hline
\end{tabular}

Fonte: Elaborado pela autora.

As questões seguintes, abordavam sobre o tema de Psicologia. Os dados gerais apontaram que a maioria dos policiais $(63,20 \%)$ "sempre" consideram o acompanhamento psicológico importante. Neste item, chama atenção as opções de "nunca" e "sempre" nas duas questões apresentadas, respondidas pelos Policiais Militares do $1^{\circ}$ Batalhão.

Tabela 02 - Resultado das respostas sobre acompanhamento psicológico

\begin{tabular}{|l|l|l|l|l|l|}
\hline Questão & Grupo & Raramente & Às vezes & Sempre & Nunca \\
\hline $\begin{array}{l}\text { Você já realizou } \\
\text { acompanhamento }\end{array}$ & $\mathbf{1}^{\circ}$ BPM & $12,84 \%$ & $15,50 \%$ & $0,91 \%$ & $\mathbf{7 0 , 6 4 \%}$ \\
\hline psicológico? & & 14 & 17 & 1 & 77 \\
\hline & & $17,46 \%$ & $3,17 \%$ & $3,17 \%$ & $76,19 \%$ \\
\hline & $\mathbf{2}^{\circ}$ BPM & 11 & 2 & 2 & 48 \\
\hline & $\mathbf{3}^{\circ}$ BPM & $10 \%$ & $10 \%$ & 0 & $80 \%$ \\
\hline & $\mathbf{4}^{\circ}$ BPM & $20 \%$ & $10 \%$ & 0 & $70 \%$ \\
\hline Resultado geral & & $14,62 \%$ & $10,84 \%$ & $1,41 \%$ & $73,11 \%$ \\
\hline & & 31 & 23 & 3 & 155 \\
\hline
\end{tabular}

RC: 93449

Disponível em: https://www.nucleodoconhecimento.com.br/psicologia/psicologia-epolicia 


\begin{tabular}{|l|l|l|l|l|l|}
\hline Questão & Grupo & Raramente & Às vezes & Sempre & Nunca \\
\hline $\begin{array}{l}\text { Você considera o } \\
\text { acompanhamento }\end{array}$ & $\mathbf{1}^{\circ}$ BPM & $3,66 \%$ & $25,68 \%$ & $\mathbf{7 0 , 6 4 \%}$ & 0 \\
\hline $\begin{array}{l}\text { psicológico } \\
\text { importante para a } \\
\text { sua profissão? }\end{array}$ & $\mathbf{2}^{\circ}$ BPM & $3,17 \%$ & $36,50 \%$ & $60,31 \%$ & 0 \\
& $\mathbf{3}^{\circ}$ BPM & $5 \%$ & $40 \%$ & $55 \%$ & 0 \\
\hline & $4^{\circ}$ BPM & 0 & 23 & 38 & \\
\hline Resultado geral & & $3,30 \%$ & $33,01 \%$ & $63,20 \%$ & $0,47 \%$ \\
\hline & & 7 & $75 \%$ & $40 \%$ & $5 \%$ \\
\hline
\end{tabular}

Fonte: Elaborado pela autora.

Em outra questão, foi abordado sobre ideação suicida e suicídio. Os resultados gerais apontaram que grande parte dos policiais "nunca" (85,84\%) pensaram em cometer suicídio. No entanto, não deve desconsiderar as respostas acerca de pensamento suicida nos policiais entrevistados, onde o resultado geral apontou nas respostas $8,49 \%$, na opção "raramente" e 5,66\%, na opção "às vezes".

Tabela 03 - Resultado das respostas sobre suicídio.

\begin{tabular}{|c|c|c|c|c|c|}
\hline Questões & Grupo & Raramente & $\begin{array}{l}\text { Às } \\
\text { vezes }\end{array}$ & Sempre & Nunca \\
\hline $\begin{array}{l}\text { Você já pensou } \\
\text { em } \quad \text { cometer }\end{array}$ & $1^{\circ} \mathrm{BPM}$ & $\begin{array}{l}9,17 \% \\
10\end{array}$ & $\begin{array}{l}8,25 \% \\
9\end{array}$ & 0 & $\begin{array}{l}82,56 \% \\
90\end{array}$ \\
\hline
\end{tabular}

RC: 93449

Disponível em: https://www.nucleodoconhecimento.com.br/psicologia/psicologia-epolicia 


\begin{tabular}{|l|l|l|l|l|l|}
\hline suicídio? & $\mathbf{2}^{\circ}$ BPM & $7,93 \%$ & $3,19 \%$ & 0 & $88,88 \%$ \\
\hline & & 5 & 2 & 56 \\
\hline $3^{\circ}$ BPM & 0 & 0 & 0 & $100 \%$ \\
\hline & $4^{\circ}$ BPM & $10 \%$ & $5 \%$ & 0 & $85 \%$ \\
\hline Resultado geral & & 2 & 1 & & 17 \\
\hline & & $8,49 \%$ & $5,66 \%$ & 0 & $85,54 \%$ \\
\hline
\end{tabular}

Fonte: Elaborado pela autora.

Acerca de tentativa de suicídio, destaca-se que foi a única questão aplicada em forma dicotômica, de sim ou não. O resultado geral apontou que $0,94 \%$ dos Policiais Militares já tentou suicídio e 99,05\% afirmaram que não.

Posteriormente, averiguado se os policiais consideravam que a profissão policial os tornou em pessoas mais "frias", grande parte $(62,73 \%)$ responderam "às vezes", conforme demonstrado na tabela a seguir:

Tabela 04 - Resultado das respostas sobre frieza.

\begin{tabular}{|c|c|c|c|c|c|}
\hline Questões & Grupo & Raramente & Às vezes & Sempre & Nunca \\
\hline $\begin{array}{l}\text { Você considera } \\
\text { que o trabalho } \\
\text { policial o tornou }\end{array}$ & $1^{\circ} \mathrm{BPM}$ & $\begin{array}{l}10,09 \% \\
11\end{array}$ & $\begin{array}{l}59,63 \% \\
65\end{array}$ & $\begin{array}{l}17,43 \% \\
19\end{array}$ & $\begin{array}{l}12,84 \% \\
14\end{array}$ \\
\hline $\begin{array}{l}\text { uma pessoa } \\
\text { "fria" }\end{array}$ & $2^{\circ} \mathrm{BPM}$ & $\begin{array}{l}6,34 \% \\
4\end{array}$ & $\begin{array}{l}66,66 \% \\
42\end{array}$ & $\begin{array}{l}14,28 \% \\
9\end{array}$ & $\begin{array}{l}12,69 \% \\
8\end{array}$ \\
\hline
\end{tabular}

RC: 93449

Disponível em: https://www.nucleodoconhecimento.com.br/psicologia/psicologia-epolicia 


\begin{tabular}{|l|l|l|l|l|l|}
\hline (insensível)? & $3^{\circ}$ BPM & $20 \%$ & $65 \%$ & $10 \%$ & $5 \%$ \\
\hline & 4 & 13 & 2 & 1 \\
\hline & $4^{\circ}$ BPM & $10 \%$ & $60 \%$ & $15 \%$ & $15 \%$ \\
\hline Resultado geral & 2 & 12 & 3 & 3 \\
\hline & $9,43 \%$ & $62,73 \%$ & $15,56 \%$ & $12,26 \%$ \\
\hline
\end{tabular}

Fonte: Elaborado pela autora.

Posteriormente, também foi investigado sobre estresse e se consideravam o trabalho policial estressante. A maioria $(61,32 \%)$ dos respondentes assinalaram "às vezes". Os dados revelaram ainda, que a maioria dos participantes consideram que "às vezes" $(52,35 \%)$ ou "sempre" $(40,56 \%)$ o trabalho laboral é estressante.

Tabela 05- Resultado das respostas sobre estresse.

\begin{tabular}{|l|l|l|l|l|l|}
\hline $\begin{array}{l}\text { Questão } \\
\text { Você se sente }\end{array}$ & Grupo & Raramente & Às vezes & Sempre & Nunca \\
\hline estressado? & $15,59 \%$ & $57,79 \%$ & $22,01 \%$ & $4,58 \%$ \\
\hline & $\mathbf{1}^{\circ}$ BPM & 17 & 63 & 24 & 5 \\
\hline & $\mathbf{2}^{\circ}$ BPM & $3,17 \%$ & $76,19 \%$ & $17,46 \%$ & $3,17 \%$ \\
\hline & & 2 & 48 & 11 & 2 \\
\hline & $\mathbf{3}^{\circ}$ BPM & $30 \%$ & $25 \%$ & $40 \%$ & $5 \%$ \\
\hline & & 6 & 5 & 8 & 1 \\
\hline & & 3 & $70 \%$ & $10 \%$ & $5 \%$ \\
\hline
\end{tabular}

RC: 93449

Disponível em: https://www.nucleodoconhecimento.com.br/psicologia/psicologia-epolicia 


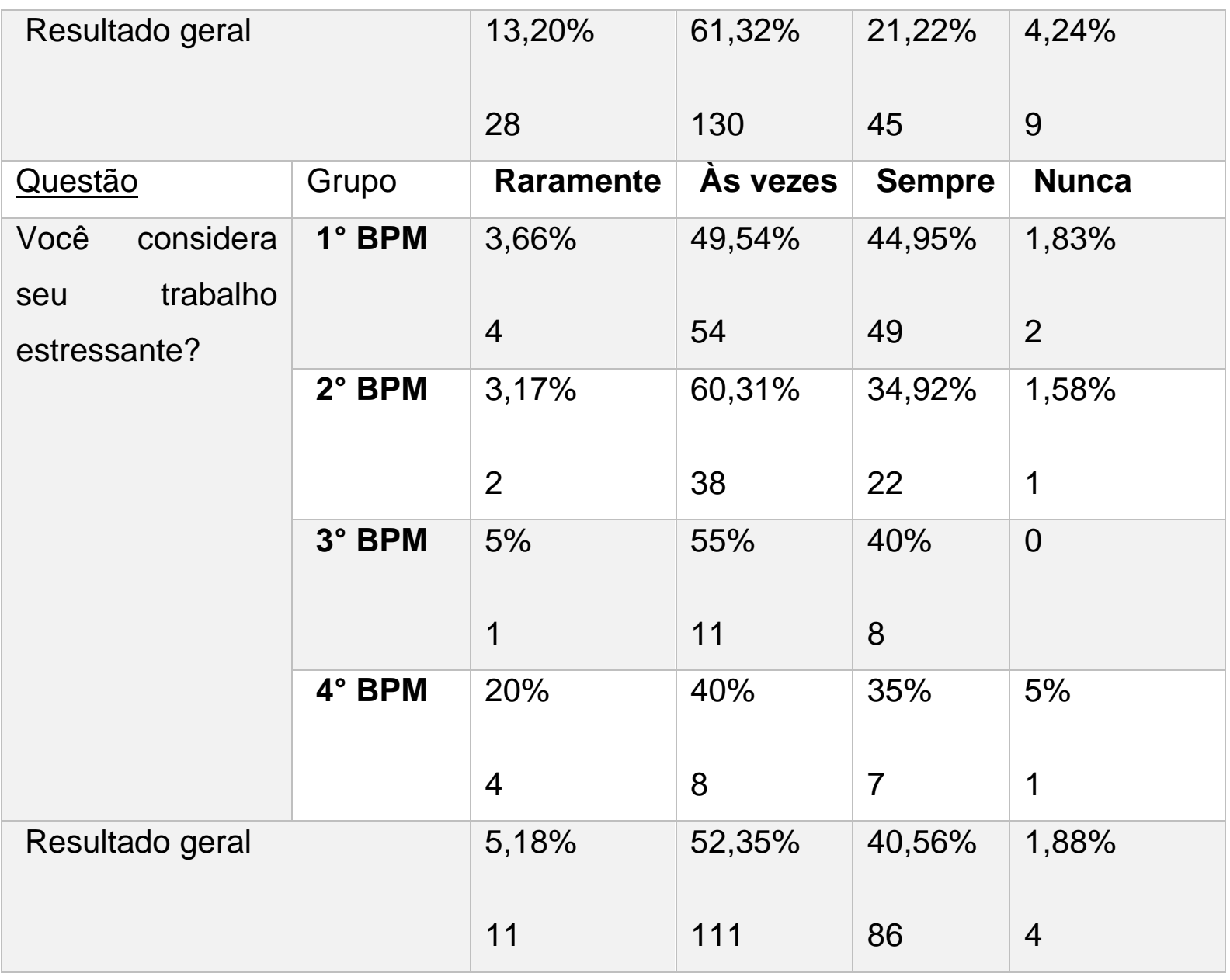

Fonte: Elaborado pela autora.

Avaliou-se em uma questão sobre a agressividade. Dessa maneira, a maioria $(47,64 \%)$ dos participantes consideram que "às vezes" o trabalho policial o tornou em uma pessoa mais agressiva.

Tabela 06 - Resultado das respostas sobre Agressividade.

\begin{tabular}{|l|l|l|l|l|l|}
\hline Questões & Grupo & Raramente & Ás vezes & Sempre & Nunca \\
\hline $\begin{array}{l}\text { Você acha que o } \\
\text { trabalho policial }\end{array}$ & $\mathbf{1}^{\circ}$ BPM & $22,93 \%$ & $50,45 \%$ & $2,75 \%$ & $23,85 \%$ \\
& 25 & 55 & 3 & 26 \\
\hline
\end{tabular}

RC: 93449

Disponível em: https://www.nucleodoconhecimento.com.br/psicologia/psicologia-epolicia 


\begin{tabular}{|c|c|c|c|c|c|}
\hline \multirow[t]{3}{*}{$\begin{array}{l}\text { o tornou uma } \\
\text { pessoa mais } \\
\text { agressiva? }\end{array}$} & $2^{\circ} \mathrm{BPM}$ & $\begin{array}{l}30,15 \% \\
19\end{array}$ & $\begin{array}{l}47,61 \% \\
30\end{array}$ & $\begin{array}{l}3,17 \% \\
2\end{array}$ & $\begin{array}{l}19,04 \% \\
12\end{array}$ \\
\hline & $3^{\circ} \mathrm{BPM}$ & $\begin{array}{l}20 \% \\
4\end{array}$ & $\begin{array}{l}35 \% \\
7\end{array}$ & $\begin{array}{l}10 \% \\
2\end{array}$ & $\begin{array}{l}35 \% \\
7\end{array}$ \\
\hline & $4^{\circ} \mathrm{BPM}$ & $\begin{array}{l}25 \% \\
5\end{array}$ & $\begin{array}{l}45 \% \\
9\end{array}$ & 0 & $\begin{array}{l}30 \% \\
6\end{array}$ \\
\hline Resultado geral & & $\begin{array}{l}25 \% \\
53\end{array}$ & $\begin{array}{l}47,64 \% \\
101\end{array}$ & $\begin{array}{l}3,30 \% \\
7\end{array}$ & $\begin{array}{l}24,05 \% \\
51\end{array}$ \\
\hline
\end{tabular}

Fonte: Elaborado pela autora.

Acerca de impulsividade e de já terem tomado alguma atitude inconsequente no exercício de sua profissão, os dados das respostas podem ser observados na tabela logo abaixo.

Tabela 07- Resultado das respostas sobre impulsividade e atitude inconsequente.

\begin{tabular}{|c|c|c|c|c|c|}
\hline Questão & Grupo & Raramente & Às vezes & Sempre & Nunca \\
\hline \multirow{7}{*}{$\begin{array}{l}\text { Você já agiu por } \\
\text { impulso em } \\
\text { alguma } \\
\text { ocorrência? }\end{array}$} & $1^{\circ} \mathrm{BPM}$ & $33,02 \%$ & $43,11 \%$ & 0 & $23,85 \%$ \\
\hline & & 36 & 47 & & 26 \\
\hline & $2^{\circ} \mathrm{BPM}$ & $31,74 \%$ & $47,61 \%$ & $1,58 \%$ & $19,04 \%$ \\
\hline & & & 30 & 1 & 12 \\
\hline & $3^{\circ} \mathrm{BPM}$ & $45 \%$ & $35 \%$ & $5 \%$ & $15 \%$ \\
\hline & & 9 & 7 & 1 & 3 \\
\hline & $4^{\circ} \mathrm{BPM}$ & $60 \%$ & $25 \%$ & 0 & $15 \%$ \\
\hline
\end{tabular}

RC: 93449

Disponível em: https://www.nucleodoconhecimento.com.br/psicologia/psicologia-epolicia 


\begin{tabular}{|c|c|c|c|c|c|}
\hline \multirow[b]{2}{*}{ Resultado geral } & & 12 & 5 & & 3 \\
\hline & & $\begin{array}{l}36,32 \% \\
77\end{array}$ & $\begin{array}{l}42,45 \% \\
90\end{array}$ & $\begin{array}{l}0,94 \% \\
2\end{array}$ & $\begin{array}{l}20,28 \% \\
43\end{array}$ \\
\hline Questão & Grupo & Raramente & Ás vezes & Sempre & Nunca \\
\hline \multirow{4}{*}{$\begin{array}{l}\text { Você já tomou } \\
\text { alguma atitude } \\
\text { inconsequente no } \\
\text { exercício de sua } \\
\text { profissão? }\end{array}$} & $1^{\circ} \mathrm{BPM}$ & $\begin{array}{l}27,52 \% \\
30\end{array}$ & $\begin{array}{l}23,85 \% \\
26\end{array}$ & 0 & $\begin{array}{l}48,62 \% \\
53\end{array}$ \\
\hline & $2^{\circ} \mathrm{BPM}$ & $\begin{array}{l}34,92 \% \\
22\end{array}$ & $\begin{array}{l}25,39 \% \\
16\end{array}$ & 0 & $\begin{array}{l}39,68 \% \\
25\end{array}$ \\
\hline & $3^{\circ} \mathrm{BPM}$ & $\begin{array}{l}45 \% \\
9\end{array}$ & $\begin{array}{l}25 \% \\
5\end{array}$ & 0 & $\begin{array}{l}30 \% \\
6\end{array}$ \\
\hline & $4^{\circ} \mathrm{BPM}$ & $\begin{array}{l}65 \% \\
13\end{array}$ & $\begin{array}{l}15 \% \\
3\end{array}$ & 0 & $\begin{array}{l}20 \% \\
4\end{array}$ \\
\hline \multicolumn{2}{|l|}{ Resultado geral } & $\begin{array}{l}34,90 \% \\
74\end{array}$ & $\begin{array}{l}23,58 \% \\
50\end{array}$ & 0 & $\begin{array}{l}41,50 \% \\
88\end{array}$ \\
\hline
\end{tabular}

Fonte: Elaborado pela autora.

A respeito sobre cansaço emocional como fator prejudicial à saúde mental dos policiais também foi avaliado. De acordo com os dados, foi possível identificar que os participantes consideram que "às vezes" $(54,71 \%)$ a atividade policial interfere no emocional. Nesse aspecto, a tabela 08 demonstra detalhadamente os resultados.

Tabela 08- Resultado das respostas sobre o emocional dos policiais.

Questão
CONHECIMENTO 


\begin{tabular}{|c|c|c|c|c|c|}
\hline \multirow{4}{*}{$\begin{array}{l}\text { Você considera } \\
\text { que à atividade } \\
\text { policial interfere no } \\
\text { seu emocional? }\end{array}$} & $1^{\circ} \mathrm{BPM}$ & $\begin{array}{l}14,67 \% \\
16\end{array}$ & $\begin{array}{l}51,37 \% \\
56\end{array}$ & $\begin{array}{l}20,18 \% \\
22\end{array}$ & $\begin{array}{l}13,76 \% \\
15\end{array}$ \\
\hline & $2^{\circ} \mathrm{BPM}$ & $\begin{array}{l}15,87 \% \\
10\end{array}$ & $\begin{array}{l}66,66 \% \\
42\end{array}$ & $\begin{array}{l}7,93 \% \\
5\end{array}$ & $\begin{array}{l}9,52 \% \\
6\end{array}$ \\
\hline & $3^{\circ} \mathrm{BPM}$ & $\begin{array}{l}21,05 \% \\
4\end{array}$ & $\begin{array}{l}42,10 \% \\
8\end{array}$ & $\begin{array}{l}21,05 \% \\
4\end{array}$ & $\begin{array}{l}15,78 \% \\
3\end{array}$ \\
\hline & $4^{\circ} \mathrm{BPM}$ & $\begin{array}{l}40 \% \\
8\end{array}$ & $\begin{array}{l}40 \% \\
8\end{array}$ & $\begin{array}{l}10 \% \\
2\end{array}$ & $\begin{array}{l}10 \% \\
2\end{array}$ \\
\hline \multicolumn{2}{|l|}{ Resultado geral } & $\begin{array}{l}16,50 \% \\
35\end{array}$ & $\begin{array}{l}54,71 \% \\
116\end{array}$ & $\begin{array}{l}16,50 \% \\
35\end{array}$ & $\begin{array}{l}12,26 \% \\
26\end{array}$ \\
\hline Questão & Grupo & Raramente & $\begin{array}{l}\text { Às } \\
\text { vezes }\end{array}$ & Sempre & Nunca \\
\hline \multirow{4}{*}{$\begin{array}{l}\text { Você considera } \\
\text { que seu trabalho } \\
\text { "prejudica" sua } \\
\text { saúde mental? }\end{array}$} & $1^{\circ} \mathrm{BPM}$ & $\begin{array}{l}20,18 \% \\
22\end{array}$ & $\begin{array}{l}50,45 \% \\
55\end{array}$ & $\begin{array}{l}12,84 \% \\
14\end{array}$ & $\begin{array}{l}16,51 \% \\
18\end{array}$ \\
\hline & $2^{\circ} \mathrm{BPM}$ & $\begin{array}{l}26,98 \% \\
17\end{array}$ & $\begin{array}{l}49,20 \% \\
31\end{array}$ & $\begin{array}{l}11,11 \% \\
7\end{array}$ & $\begin{array}{l}12,69 \% \\
8\end{array}$ \\
\hline & $3^{\circ} \mathrm{BPM}$ & $\begin{array}{l}10,52 \% \\
2\end{array}$ & $\begin{array}{l}57,89 \% \\
11\end{array}$ & $\begin{array}{l}15,78 \% \\
3\end{array}$ & $\begin{array}{l}15,78 \% \\
3\end{array}$ \\
\hline & $4^{\circ} \mathrm{BPM}$ & $\begin{array}{l}25 \% \\
5\end{array}$ & $\begin{array}{l}35 \% \\
7\end{array}$ & $\begin{array}{l}5 \% \\
1\end{array}$ & $\begin{array}{l}35 \% \\
7\end{array}$ \\
\hline \multicolumn{2}{|l|}{ Resultado geral } & $\begin{array}{l}21,69 \% \\
46\end{array}$ & $\begin{array}{l}49,05 \% \\
104\end{array}$ & $\begin{array}{l}12,26 \% \\
26\end{array}$ & $\begin{array}{l}16,98 \% \\
36\end{array}$ \\
\hline
\end{tabular}

RC: 93449

Disponível em: https://www.nucleodoconhecimento.com.br/psicologia/psicologia-epolicia 


\begin{tabular}{|l|l|l|l|l|l|}
\hline Questão & Grupo & Raramente & $\begin{array}{l}\text { Ás } \\
\text { vezes }\end{array}$ & Sempre & Nunca \\
\hline $\begin{array}{l}\text { Você se sente } \\
\text { emocionalmente } \\
\text { cansado após um } \\
\text { dia de trabalho? }\end{array}$ & $\mathbf{1}^{\circ}$ BPM & $10,09 \%$ & $53,21 \%$ & $33,02 \%$ & $3,66 \%$ \\
\hline & $\mathbf{2}^{\circ}$ BPM & $12,69 \%$ & $50,79 \%$ & $34,92 \%$ & $1,58 \%$ \\
\hline & $\mathbf{3}^{\circ}$ BPM & $30 \%$ & $25 \%$ & $35 \%$ & $10 \%$ \\
\hline & $4^{\circ}$ BPM & $25 \%$ & $45 \%$ & $20 \%$ & $10 \%$ \\
\hline Resultado geral & & $14,15 \%$ & $49,05 \%$ & $32,54 \%$ & $4,24 \%$ \\
\hline
\end{tabular}

Fonte: Elaborado pela autora.

Avaliou-se em uma questão sobre a realização de horas extras ocasionar prejuízo na saúde mental dos profissionais. Observou-se que foi unânime entre a maioria dos policiais dos quatro Batalhões, a opção "sempre", com $52,35 \%$.

Tabela 09 - Resultado das respostas sobre realização de hora extra.

\begin{tabular}{|l|l|l|l|l|l|}
\hline Questão & Grupo & Raramente & Às vezes & Sempre & Nunca \\
\hline $\begin{array}{l}\text { Você considera } \\
\text { que realizar }\end{array}$ & $\mathbf{1}^{\circ}$ BPM & $7,33 \%$ & $33,02 \%$ & $56,88 \%$ & $2,75 \%$ \\
$\begin{array}{l}\text { horas extras de } \\
\text { trabalho é } \\
\text { prejudicial para }\end{array}$ & $\mathbf{2}^{\circ}$ BPM & 8 & 36 & 62 & 3 \\
\hline
\end{tabular}

RC: 93449

Disponível em: https://www.nucleodoconhecimento.com.br/psicologia/psicologia-epolicia 


\begin{tabular}{|l|l|l|l|l|l|}
\hline $\begin{array}{l}\text { sua saúde } \\
\text { mental? }\end{array}$ & $\mathbf{3}^{\circ}$ BPM & $5 \%$ & $40 \%$ & $40 \%$ & $15 \%$ \\
& & 1 & 8 & 8 & 3 \\
\hline & $4^{\circ}$ BPM & 0 & $40 \%$ & $50 \%$ & $10 \%$ \\
\hline Resultado geral & & $5,66 \%$ & $37,26 \%$ & $52,35 \%$ & $4,17 \%$ \\
\hline
\end{tabular}

Fonte: Elaborado pela autora.

Posteriormente, também foi averiguado sobre ansiedade e insônia entre os participantes. Parte dos entrevistados consideraram que a atividade policial os tornou mais ansiosos, representando pela opção "às vezes" com 52,83\%. A tabela 10 demonstra detalhadamente os resultados:

Tabela 10- Resultado das respostas sobre ansiedade e insônia.

\begin{tabular}{|l|l|l|l|l|l|}
\hline Questão & Grupo & Raramente & Às vezes & Sempre & Nunca \\
\hline $\begin{array}{l}\text { Você considera } \\
\text { que sua atividade } \\
\text { profissional } \\
\text { tornou mais } \\
\text { ansioso (a)? }\end{array}$ & $\mathbf{1}^{\circ}$ BPM & $12,84 \%$ & $53,21 \%$ & $15,59 \%$ & $18,34 \%$ \\
& $\mathbf{2}^{\circ}$ BPM & $14,28 \%$ & $61,90 \%$ & $9,52 \%$ & $14,28 \%$ \\
& $\mathbf{3}^{\circ}$ BPM & $25 \%$ & $40 \%$ & $20 \%$ & $15 \%$ \\
\hline & $\mathbf{4}^{\circ}$ BPM & $20 \%$ & $35 \%$ & $20 \%$ & $25 \%$ \\
& & 4 & 7 & 4 & 5 \\
\hline
\end{tabular}

RC: 93449

Disponível em: https://www.nucleodoconhecimento.com.br/psicologia/psicologia-epolicia 


\begin{tabular}{|c|c|c|c|c|c|}
\hline \multicolumn{2}{|l|}{ Resultado geral } & \multirow{2}{*}{$\begin{array}{l}15,09 \% \\
32 \\
\text { Raramente }\end{array}$} & \multirow{2}{*}{$\begin{array}{l}52,83 \% \\
112 \\
\text { Às vezes }\end{array}$} & \multirow{2}{*}{$\begin{array}{l}14,62 \% \\
31 \\
\text { Sempre }\end{array}$} & \multirow{2}{*}{$\begin{array}{l}17,45 \% \\
37 \\
\text { Nunca }\end{array}$} \\
\hline Questão & Grupo & & & & \\
\hline \multirow{8}{*}{$\begin{array}{l}\text { Você tem sofrido } \\
\text { com insônia? }\end{array}$} & $1^{\circ} \mathrm{BPM}$ & $21,10 \%$ & $42,20 \%$ & $10,09 \%$ & $26,60 \%$ \\
\hline & & 23 & 46 & 11 & 29 \\
\hline & $2^{\circ} \mathrm{BPM}$ & $19,04 \%$ & $49,20 \%$ & $12,69 \%$ & $19,04 \%$ \\
\hline & & 12 & 31 & 8 & 12 \\
\hline & $3^{\circ} \mathrm{BPM}$ & $30 \%$ & $20 \%$ & $15 \%$ & $35 \%$ \\
\hline & & 6 & 4 & 3 & 7 \\
\hline & $4^{\circ} \mathrm{BPM}$ & $20 \%$ & $35 \%$ & $15 \%$ & $30 \%$ \\
\hline & & 4 & 7 & 3 & 6 \\
\hline \multirow{2}{*}{\multicolumn{2}{|c|}{ Resultado geral }} & $21,22 \%$ & $41,50 \%$ & $11,79 \%$ & $25,47 \%$ \\
\hline & & 45 & 88 & 25 & 54 \\
\hline
\end{tabular}

Fonte: Elaborado pela autora.

Levantou-se uma questão referente a realização profissional. Os dados demonstraram que a maioria dos militares apontaram que "sempre" $(53,77 \%)$ sentem-se felizes com o cargo exercido.

Tabela 11- Resultado das respostas sobre ansiedade e insônia.

\begin{tabular}{|l|l|l|l|l|l|}
\hline Questão & Grupo & Raramente & Às vezes & Sempre & Nunca \\
\hline & $\mathbf{1}^{\circ}$ BPM & $5,50 \%$ & $33,02 \%$ & $54,12 \%$ & $7,33 \%$ \\
& & 6 & 36 & 59 & 8 \\
\hline
\end{tabular}

RC: 93449

Disponível em: https://www.nucleodoconhecimento.com.br/psicologia/psicologia-epolicia 


\begin{tabular}{|c|c|c|c|c|c|}
\hline & $2^{\circ} \mathrm{BPM}$ & $\begin{array}{l}3,17 \% \\
2\end{array}$ & $\begin{array}{l}33,33 \% \\
28\end{array}$ & $\begin{array}{l}60,31 \% \\
38\end{array}$ & $\begin{array}{l}3,17 \% \\
2\end{array}$ \\
\hline & $3^{\circ} \mathrm{BPM}$ & $\begin{array}{l}10 \% \\
2\end{array}$ & $\begin{array}{l}40 \% \\
8\end{array}$ & $\begin{array}{l}35 \% \\
7\end{array}$ & $\begin{array}{l}15 \% \\
3\end{array}$ \\
\hline $\begin{array}{lll}\text { Você está } & \text { feliz } \\
\text { com } 0 & \text { cargo } \\
\text { exercido? } & \end{array}$ & $4^{\circ} \mathrm{BPM}$ & $\begin{array}{l}5 \% \\
1\end{array}$ & $\begin{array}{l}35 \% \\
7\end{array}$ & $\begin{array}{l}50 \% \\
10\end{array}$ & $\begin{array}{l}10 \% \\
2\end{array}$ \\
\hline Resultado geral & & $\begin{array}{l}5,18 \% \\
11\end{array}$ & $\begin{array}{l}33,96 \% \\
72\end{array}$ & $\begin{array}{l}53,77 \% \\
114\end{array}$ & $\begin{array}{l}7,07 \% \\
15\end{array}$ \\
\hline Questão & Grupo & Raramente & Às vezes & Sempre & Nunca \\
\hline Você sente & $1^{\circ} \mathrm{BPM}$ & $\begin{array}{l}9,17 \% \\
10\end{array}$ & $\begin{array}{l}37,61 \% \\
41\end{array}$ & $\begin{array}{l}32,11 \% \\
35\end{array}$ & $\begin{array}{l}21,10 \% \\
23\end{array}$ \\
\hline $\begin{array}{l}\text { vontade de mudar } \\
\text { de profissão? }\end{array}$ & $2^{\circ} \mathrm{BPM}$ & $\begin{array}{l}14,28 \% \\
9\end{array}$ & $\begin{array}{l}44,44 \% \\
28\end{array}$ & $\begin{array}{l}25,39 \% \\
16\end{array}$ & $\begin{array}{l}15,87 \% \\
10\end{array}$ \\
\hline & $3^{\circ} \mathrm{BPM}$ & $\begin{array}{l}25 \% \\
5\end{array}$ & $\begin{array}{l}35 \% \\
7\end{array}$ & $\begin{array}{l}20 \% \\
4\end{array}$ & $\begin{array}{l}20 \% \\
4\end{array}$ \\
\hline & $4^{\circ} \mathrm{BPM}$ & $\begin{array}{l}5 \% \\
1\end{array}$ & $\begin{array}{l}40 \% \\
8\end{array}$ & $\begin{array}{l}15 \% \\
3\end{array}$ & $\begin{array}{l}40 \% \\
8\end{array}$ \\
\hline \multicolumn{2}{|l|}{ Resultado geral } & $\begin{array}{l}11,79 \% \\
25\end{array}$ & $\begin{array}{l}39,62 \% \\
84\end{array}$ & $\begin{array}{l}27,35 \% \\
58\end{array}$ & $\begin{array}{l}21,22 \% \\
45\end{array}$ \\
\hline
\end{tabular}

Fonte: Elaborado pela autora.

RC: 93449

Disponível em: https://www.nucleodoconhecimento.com.br/psicologia/psicologia-epolicia 
Por fim, verificou se os participantes se sentiam valorizados enquanto Policiais Militares. A maioria dos respondentes assinalaram em "nunca" (33,96\%) e "raramente (32,54\%), apontando um descontentamento enquanto sentirem valorização profissional.

Tabela 12 - Resultado das respostas sobre valorização profissional.

\begin{tabular}{|c|c|c|c|c|c|}
\hline Questão & Grupo & Raramente & Às vezes & Sempre & Nunca \\
\hline $\begin{array}{l}\text { Você } \\
\text { considera } \\
\text { valorizado como }\end{array}$ & $1^{\circ} \mathrm{BPM}$ & $\begin{array}{l}30,27 \% \\
33\end{array}$ & $\begin{array}{l}27,52 \% \\
30\end{array}$ & $\begin{array}{l}1,83 \% \\
2\end{array}$ & $\begin{array}{l}40,36 \% \\
44\end{array}$ \\
\hline Policial Militar? & $2^{\circ} \mathrm{BPM}$ & $\begin{array}{l}34,92 \% \\
22\end{array}$ & $\begin{array}{l}33,33 \% \\
21\end{array}$ & $\begin{array}{l}3,17 \% \\
2\end{array}$ & $\begin{array}{l}28,57 \% \\
18\end{array}$ \\
\hline & $3^{\circ} \mathrm{BPM}$ & $\begin{array}{l}30 \% \\
6\end{array}$ & $\begin{array}{l}30 \% \\
6\end{array}$ & $\begin{array}{l}10 \% \\
2\end{array}$ & $\begin{array}{l}30 \% \\
6\end{array}$ \\
\hline & $4^{\circ} \mathrm{BPM}$ & $\begin{array}{l}40 \% \\
8\end{array}$ & $\begin{array}{l}35 \% \\
7\end{array}$ & $\begin{array}{l}5 \% \\
1\end{array}$ & $\begin{array}{l}20 \% \\
4\end{array}$ \\
\hline \multicolumn{2}{|l|}{ Resultado geral } & $\begin{array}{l}32,54 \% \\
69\end{array}$ & $\begin{array}{l}30,18 \% \\
64\end{array}$ & $\begin{array}{l}3,30 \% \\
7\end{array}$ & $\begin{array}{l}33,66 \% \\
72\end{array}$ \\
\hline
\end{tabular}

Fonte: Elaborado pela autora.

\section{DISCUSSÃO}

Salienta-se que o presente estudo buscou gerar informações que propiciassem a compreensão do impacto que à atividade policial pode ocasionar no estado mental e

RC: 93449

Disponível em: https://www.nucleodoconhecimento.com.br/psicologia/psicologia-epolicia 
na vida pessoal desses indivíduos, além de suscitar a relevância da construção de estratégias preventivas que visem a saúde mental dos profissionais.

Verifica-se que os dados apresentados retratam como os policiais se sentem e percebem a si mesmo em sua atuação profissional, levando em consideração que a veracidade do estudo dependeria da autenticidade das respostas dadas pelos Policiais Militares.

Para melhor compreender os dados levantados, os resultados serão divididos nas seguintes categorias: 1) Relacionamento familiar; 2) Prejuízo emocional; 3) estresse ocasionado pela atividade laboral; 4) Agressividade; 5) Ansiedade e insônia; 6) Suicídio; 7) Necessidade de acompanhamento psicológico; e 8) Valorização enquanto Policial Militar.

\subsection{RELACIONAMENTO FAMILIAR}

De acordo com os autores Derenusson e Jablonski (2010) uma queixa comum entre as esposas de Policiais Militares é a mudança indesejável de identidade após a entrada na corporação, em muitos casos apresentando apatia à família, rigidez e até agressividade. No entanto, essa percepção não é observada apenas pelo cônjuge, já que os próprios militares identificam essas mudanças.

Essa realidade apontada pelos autores, vai de encontro com os dados obtidos apresentado na tabela 01, onde a maioria dos policiais dos Batalhões alcançados, consideram que "às vezes" (61,32\%) sua atividade laboral já afetou seu relacionamento com os familiares. Dessa maneira, esse dado reflete com o que Santana e Sabino (2020) apontam em afirmar que o policial militar tende a diminuir suas emoções com a família, em alguns casos, havendo um processo de distanciamento, o que pode culminar em problemas familiares diversos. Verifica-se também, que devido a situações traumáticas vivenciados no trabalho, esses

RC: 93449

Disponível em: https://www.nucleodoconhecimento.com.br/psicologia/psicologia-epolicia 
profissionais acabam em apresentar dificuldade em dispor de apoio emocional aos familiares.

\subsection{PREJUÍZO EMOCIONAL}

Conforme apontou Oliveira e Faiman (2019, p. 614): "O trabalho do militar parece afetar a vida dos profissionais. A proximidade com a violência, a experiência de sofrer riscos e a rigidez no seguimento das normas são fatores que marcam a sua experiência." Assim, conforme corrobora os autores, o trabalho policial pode afetar no modo de ser e no emocional quando o indivíduo ingressa na corporação.

Tal constatação aproxima-se com as respostas obtidas dos participantes demonstrado na tabela 08 , ao serem questionados se a atividade policial interfere no emocional, onde $54,71 \%$ afirmaram que "às vezes" ou "sempre" (16,50\%) sentem a interferência no emocional.

$\mathrm{Na}$ amostra do estudo, $62,73 \%$ dos participantes consideram que "às vezes" e $(15,56 \%)$ "sempre" o trabalho policial influenciou em torná-los uma pessoa mais fria. Diante disso, Oliveira e Faiman (2019, p. 615) ressaltam que: "as relações mais próximas dos policiais, em especial as conjugais, parecem ser prejudicadas pelo que eles denominam como frieza emocional desenvolvida como característica para suportar a profissão." Nesse sentido, é compreendido que os Policiais Militares acabam desenvolvendo certa frieza, devido a encontrar situações em sua carreira que necessitam de um controle emocional, todavia, acabam levando esse modo de agir para as suas relações pessoais.

A realização de horas extras é um recurso que proporciona uma renda extra ao profissional, e que os militares exercem frequentemente. Todavia, sua prática excessiva pode ocasionar prejuízo na vida do policial. No que se refere a esse questionamento, a maioria dos entrevistados apontaram que $(52,35 \%)$ "sempre"

RC: 93449

Disponível em: https://www.nucleodoconhecimento.com.br/psicologia/psicologia-epolicia 
consideravam a realização de horas extras de trabalho como prejudicial à saúde mental.

Essa situação reflete com a mesma encontrada por Oliveira e Santos (2010) quando retratam que as horas de repouso e lazer poderiam ser um fato a contribuir no equilíbrio mental, no entanto, grande parte dos militares em horários de folga, prestam seus serviços em busca de complementar a renda, comprometendo assim o seu momento de descanso. Frente a essa realidade, o policial acaba tendo um desgaste físico e mental ainda maior.

Assim, compreende-se que os Policiais Militares na pesquisa reconhecem 0 desgaste que o trabalho extra ocasiona, todavia, parece que a percepção desse prejuízo não interfere na decisão em interromper essa prática.

\subsection{ESTRESSE OCASIONADO PELA ATIVIDADE LABORAL}

Na pesquisa de 212 respondentes, 52,35\% relataram que "às vezes" ou, "sempre" $(40,56 \%)$ consideram seu trabalho estressante. Esse resultado vai de encontro com o que aponta a literatura em geral, quando define a profissão do Policial Militar como uma das profissões que ocasiona maiores índices de estresse. Verifica-se que o estresse é uma realidade na profissão, e que pode influenciar em seu comportamento dentro e fora de sua atividade laboral, além de apresentar diversas doenças que se relacionam aos fatores estressantes da sua profissão (SANTANA; SABINO, 2020).

Nesse sentido, analisando a percepção dos militares em sentir-se estressado, os dados revelam que a maioria $(61,32 \%)$ dos policiais se sentem" às vezes" ou $(21,22 \%)$ "sempre" estressados. Vale destacar que no item relacionado ao estresse, percebe-se que os resultados dos quatro batalhões alcançados não diferem nas respostas, demonstrando que de fato a exposição a situações de risco, e com

RC: 93449

Disponível em: https://www.nucleodoconhecimento.com.br/psicologia/psicologia-epolicia 
ocorrências que geram desgaste físico e emocional, são fatores que contribuem para o desenvolvimento do estresse.

Dessa maneira, compreende-se que o estresse é um dos principais sintomas desencadeantes da atividade Policial, e mais uma vez mostra a necessidade que amparem o bem-estar psicológico dos Policiais Militares, salientando que se não tiver esse cuidado necessário, poderá desencadear sérios riscos ao indivíduo que lida rotineiramente com situações estressantes, como o desenvolvimento de outras patologias, ou até na falta de controle de atitudes agressivas, salientando que, esses fatores constituem risco direto para a sociedade em geral que necessita da prestação de seus serviços.

\subsection{AGRESSIVIDADE}

No que se refere sobre se a atividade policial influenciou em torná-los uma pessoa agressiva, a maioria $(47,64 \%)$ dos respondentes assinalou que "às vezes" consideravam que à agressividade tinha relação a partir da sua atividade laboral.

Rezende e Cavazza (2002) discorrem que a atuação policial é permeada por situações que envolve violência extrema, incluindo o risco de vida eminente, exigindo que o profissional esteja sempre atento e em prontidão, já que a imprevisibilidade é característica deste serviço. Nesse sentido, entende-se que na função enquanto Policial Militar no combate a violência, em algumas situações "se faz necessário o uso da força, sendo este o único agente possuidor de tal poder representante do estado " (SILVA, 2007, p. 03). Todavia, em alguns militares, essa atitude pode extrapolar os parâmetros dispostos na lei, quando agem com atitudes inconsequentes no exercício de sua profissão.

A respeito sobre atitudes inconsequentes na atuação enquanto Policial Militar, a maioria dos participantes apontaram que $(41,50 \%)$ "nunca" tiveram essa atitude, $(23,58 \%)$ afirmaram que "às vezes" e $(34,90 \%)$ responderam que "raramente". Por

RC: 93449

Disponível em: https://www.nucleodoconhecimento.com.br/psicologia/psicologia-e- 
conseguinte, quando questionado se já agiu por impulso em alguma ocorrência, o maior percentual apontou $(42,45 \%)$ em "às vezes".

Compreende-se que a conduta do Policial deve ser sempre ilibada, inclusive fora do expediente, devendo manter o controle apropriado nas ocorrências policiais. Contudo, em conformidade com Oliveira e Santos (2020) a clareza na atuação e o desempenho com equilíbrio deve ultrapassar o cansaço físico e emocional, já que tais fatores podem influenciar de forma negativa a conduta apropriada, podendo ocasionar intolerância e falta de controle.

No entanto, seria inoportuno não ponderar a existência de casos em que a polícia ultrapassa na sua conduta contra os civis. Dessa maneira, apesar de muitos policiais repudiarem condutas agressivas, estas ainda ocorrem, cabendo destacar os resultados do presente estudo onde os próprios policiais avaliaram que "às vezes" já agiram por impulso em alguma ocorrência.

\subsection{ANSIEDADE E INSÔNIA}

As pesquisas apontam que as condições laborais dos policiais podem torná-los vulneráveis a desenvolver sintomas de ansiedade e distúrbio de sono. (SOUSA, 2018). Dessa maneira, a pesquisa também averiguou se os policiais consideram que a atividade policial os tornou pessoas mais ansiosas. Os resultados apontaram que a maioria $(52,83 \%)$ dos participantes consideram que "às vezes" sua atividade laboral contribuiu para os sintomas de ansiedade. Sobre ansiedade, entende-se como uma: "antecipação de uma ameaça futura, sendo associada a comportamentos como tensão muscular, vigilância em preparação a um perigo futuro, além de comportamentos de cautela e esquiva". (SOUSA, 2018, p. 48)

Verifica-se que a ansiedade moderada pode ser adaptativa, porém quando vivenciada por longos períodos, pode ocasionar o aparecimento de transtornos mais severos, podendo surgir de maneira isolada ou com outras comorbidades, como a

RC: 93449

Disponível em: https://www.nucleodoconhecimento.com.br/psicologia/psicologia-epolicia 
depressão e transtorno de pânico. Nesse sentido, ratifica que a profissão policial pode ocasionar sintomas de ansiedade, tendo em vista que o profissional constantemente se depara com situações estressantes e que exigem eficácia no seu desempenho, o que corrobora com os resultados apontados onde a maioria dos participantes afirmaram que a profissão o tornou pessoas mais ansiosas.

O estudo também investigou a percepção dos policiais acerca da insônia, tendo em vista que a qualidade do sono do policial é um relevante aspecto para a promoção da qualidade de vida e o bom desempenho de suas atividades laborais. Assim, a maioria dos respondentes dos quatro batalhões estudados, avaliaram que "às vezes" $(41,50 \%)$ sentem-se prejudicados com a insônia. Diante disso, Bernardo (Et al., 2015) ressalta que os profissionais que trabalham em horários noturnos e rotativos assim como os Policiais Militares, acabam sofrendo modificações no ritmo biológico, e que podem afetar diretamente os aspectos físicos e mentais provocados pelas alterações nos horários de sono e descanso. Além disso, as inversões de turnos diminuem o tempo diurno com a família, lazer e descanso que podem afetar as questões sociais essenciais do indivíduo.

\subsection{SUICÍDIO}

Denota-se que a incidência de suicídio nas Corporações Militares ocorre de maneira mais elevada ao comparado com a população em geral. A revista Veja, em 1999, apontou que a taxa de suicídio entre os Policiais Militares era sete vezes maior do que de pessoas Civis.

Sendo averiguado o assunto, foi perguntado aos participantes se em algum momento já pensaram em cometer suicídio. Os resultados apontaram que 8,49\% "raramente" já pensaram, $5,66 \%$ "às vezes" e $85,84 \%$ "nunca".

No que tange sobre a tentativa de suicídio, a maioria dos policiais representado por $98,58 \%$ afirmaram que nunca tentaram, e 0,94\% afirmaram que já tentaram.

RC: 93449

Disponível em: https://www.nucleodoconhecimento.com.br/psicologia/psicologia-epolicia 
Destaca-se que o suicídio é uma realidade grave que acontece entre os Policiais Militares, e de acordo com Putti (2021), no Brasil o número de policiais que cometem suicídio é maior do que com os que morrem durante o serviço. Frente a essa realidade, denota a importância de falar sobre suicídio dentro das Corporações, não desconsiderando que essa realidade ainda é frequente entre esses profissionais, e que a prevenção é a melhor maneira para evitar que os números de suicídio entre policiais se expandem ainda mais.

\subsection{NECESSIDADE DE ACOMPANHAMENTO PSICOLÓGICO}

Os estudos apontam que os policiais apresentam resistência em buscar ajuda diante dos sintomas emocionais e psicológico. Para tentar compreender a percepção dos policiais acerca de como avaliam a relevância da Psicoterapia na profissão, os dados apontaram que a maioria dos participantes $(73,11 \%)$ "nunca" realizaram acompanhamento psicológico. Entretanto, quando avaliado se consideravam o acompanhamento psicológico importante para a profissão, a frequência $(63,20 \%)$ "sempre" representou a resposta da maioria dos policiais.

Chamo à atenção do leitor para os resultados dos Policiais Militares lotados no $1^{\circ}$ Batalhão, que embora reconheçam a importância do acompanhamento psicológico $(70,64 \%)$ para a sua profissão, o mesmo quantitativo $(70,64 \%)$ afirmou que "nunca" realizaram acompanhamento psicológico.

Partindo desse resultado, vale a reflexão do que poderia ocasionar o distanciamento da busca pela ajuda psicológica, já que pela percepção dos próprios militares é identificado a relevância da Psicologia no lugar de ajuda para a profissão policial, ainda mais, quando a Corporação dispõe de uma Policlínica destinada para os atendimentos de policiais e familiares.

Em contrapartida, ainda prevalece como característica da cultura policial, a imagem de força, coragem e invencibilidade que muitas vezes a sociedade e a própria

RC: 93449

Disponível em: https://www.nucleodoconhecimento.com.br/psicologia/psicologia-epolicia 
Corporação assim reveste o profissional, não deixando espaço para as manifestações de fraquezas, angústias e medos, o que acaba distanciando o policial do lugar de ajuda. (PUTTI, 2021)

Pelos dados obtidos, verifica-se que a atividade laboral de um Policial Militar pode ocasionar danos psicológicos se não forem cuidados, ressaltando que a prevenção seria a maneira mais indicada para evitar problemas maiores, tendo em vista que quando o policial busca ajuda psicológica seu estado emocional já se encontra fragilizado demasiadamente.

Destaca-se que o acompanhamento psicológico é tão importante como o preparo físico dos policiais para ingressar na Corporação Militar, e o investimento do poder público poderia contribuir para profissionais mais saudáveis em relação a saúde mental e mais eficazes na realização de suas atividades profissionais.

\subsection{VALORIZAÇÃO ENQUANTO POLICIAL MILITAR}

Embora as dificuldades estejam presentes na profissão do Policial Militar, a maioria $(53,77 \%)$ indicou "sempre" estar feliz com o cargo exercido, conforme apresentado na tabela 11. No entanto, na tabela 12, chama à atenção as respostas dos participantes quando questionados sobre se considerar valorizado enquanto Policial Militar, onde a maioria dos respondentes assinalaram a opção "nunca" (33, 96\%) seguido de "raramente" (32,54\%).

Em outra questão, avaliado se os policiais sentem vontade de mudar de profissão, as opções que apresentaram a maior porcentagem foram "às vezes" $(39,62 \%)$ e "sempre" (27,35\%). Em hipótese, seria indicado novas investigações a respeito do que levariam os profissionais ao desejo de mudar de profissão e se sentirem desvalorizados. Denota-se que abrir um espaço para ouvir os profissionais, poderia ser uma estratégia eficaz para compreender os possíveis desapontamentos dos policiais e estudar estratégias para reverter os dessabores da profissão.

RC: 93449

Disponível em: https://www.nucleodoconhecimento.com.br/psicologia/psicologia-epolicia 


\section{CONSIDERAÇÕES FINAIS}

O presente estudo buscou averiguar quais as principais inquietações que afligem nas mentes dos Policiais Militares e suas possíveis consequências em sua vida e no trabalho, sendo uma pesquisa independente e sem vínculo institucional, que foi desenvolvida na Cidade de Rio Branco, e no interior do Estado do Acre. Salienta-se que a Corporação da Polícia Militar teve um papel imprescindível para a realização da pesquisa, apoiando no desenvolvimento do estudo e contribuindo com informações que visassem a compreensão do universo Militar, a fim de garantir a melhor investigação no tema abordado.

Destaca-se que, no Brasil ainda há poucos estudos com levantamento de dados acerca da percepção dos próprios Policiais Militares, o que ocasionou dificuldades em encontrar assuntos que viabilizassem essa realidade, não havendo nenhum outro trabalho anterior desenvolvido no presente Estado. Assim, a proposta da pesquisa era alcançar o maior número de policiais em atividade, todavia, não foi possível uma abrangência maior devido a muitos profissionais estarem de licença, férias ou afastados provisoriamente durante a execução do estudo.

Vale frisar que este trabalho tencionou levantar dados quali-quantitativo, no intuito de investigar como os Policiais Militares tinham a percepção da própria saúde mental. Os resultados retratados pelos profissionais pareciam designar que os militares tinham consciência acerca do próprio estado mental.

Todavia, destaca-se que apesar dos resultados mostrarem que maioria dos policiais consideram sempre importante o acompanhamento psicológico durante a sua carreira profissional, um outro aspecto é observado: a maioria também afirmou que nunca tiveram a experiência de atendimento psicológico. Neste ponto, vale ressaltar que os Militares podem ser atendidos por profissionais de Psicologia na Unidade de atendimento da Polícia Militar (Policlínica), sendo uma porta de entrada para o contato psicológico se assim quisessem.

RC: 93449

Disponível em: https://www.nucleodoconhecimento.com.br/psicologia/psicologia-e- 
Partindo desse pressuposto, poderia ser discutido o que motivaria não buscarem atendimento psicológico, tendo em vista, que através das respostas dos mesmos, é possível verificar como a atividade policial afeta a vida do policial em exercício. Em contrapartida, poderia ser observado que no militarismo ainda existem barreiras que devem ser ultrapassadas, como a dificuldade em demonstrar fragilidades emocionais o que distancia o militar da relação de ajuda, podendo caracterizar a procura por atendimento psicológico como um sinal de fraqueza.

Verifica-se que os Batalhões Militares da cidade de Rio Branco, não dispõem em seu quadro de funcionários um psicólogo, e nem ao menos no Curso de Formação de Praças (CFP) uma disciplina que viabilizasse essa ciência, denotando ainda mais o distanciamento da Psicologia com o Policial Militar desde a sua formação, destacando que a atuação clínica psicológica apenas em consultório excluí as potencialidades da Psicologia, já que o militar precisa fazer estratégias para chegar ao consultório em anonimato, ou na maioria das vezes, não procura o atendimento psicológico.

Conclui-se que se faz necessário a implementação de Políticas Públicas relacionadas ao atendimento psicológico sobre o adoecimento físico e mental de policiais do Estado do Acre, além de Políticas institucionais promovida pelos próprios Batalhões, a fim de intencionar o cuidado mental não apenas no aguardo que o policial denote necessidade e busque auxílio psicológico, mais também em caráter preventivo, ingressando a Psicologia nas Instituições Militares no Estado do Acre para ir além dos consultórios, intervindo que os policiais tenham um maior nível de autocontrole de impulsos e emoções em sua prática laboral, o que redundaria em favor da Corporação, do próprio policial, e sobretudo, da sociedade que necessita contar com a eficiência de seus serviços.

\section{AGRADECIMENTOS}

RC: 93449

Disponível em: https://www.nucleodoconhecimento.com.br/psicologia/psicologia-e- 
Agradeço ao Comandante Geral CEL. PM Paulo César, pelo consentimento na realização da pesquisa, agradeço ao CEL. PM Giovane, MAJ. PM Edvan, MAJ. PM Velásquez, MAJ. PM Airton e MAJ PM Russo pela colaboração e apoio no processo da pesquisa, ao TEN PM Marcos pelas orientações no trabalho e por fim, agradeço ao SGT PM Ênio por todo o auxílio prestado para o alcance dos participantes.

\section{REFERÊNCIAS}

BRASIL, Cristina Índio. Acompanhamento psicológico ajuda policiais militares a enfrentar momentos de tensão. Disponível em:<https://memoria.ebc.com.br/noticias/brasil/2013/06/acompanhamentopsicologic o-ajuda-policiais-militares-a-enfrentar-momentos-de> Acesso em: 20 nov.2020.

BERNARDO, Valdeni Manoel et al. Efeitos do Trabalho em Turnos na Qualidade do Sono de Policiais: Uma Revisão Sistemática. Rev Cub Med Mil, Ciudad de la Habana ,v. 44, n. 3, p. 334-345, sept. 2015 . Disponivel em: $<$ http://scielo.sld.cu/scielo.php?script=sci_arttext\&pid=S013865572015000300007\&ln $\mathrm{g}=\mathrm{es} \& \mathrm{nrm}=\mathrm{iso}>$. Acesso em: 09 jun. 2021.

DERENUSSON, F. C., \& JABLONSKI, B. (2010). Sob fogo cruzado: o impacto do trabalho policial militar sobre a família do policial. Aletheia, (32). de http://pepsic.bvsalud.org/pdf/aletheia/n32/n32a03.pdf.

LIPP, Marilda Novaes. Os efeitos negativos do estresse emocional no organismo humano e como gerenciá-lo. Instituto de psicologia e controle do estresse. Estudo sobre o estresse. Disponível em: http://www.estresse.com.br/. Acesso em: 19 nov.2020.

LUSTOSA, Daniela Bizzotto Soares; GONÇALVES, Heli José. Psicologia na Polícia Militar: desafios do âmbito da cultura organizacional. Rev. Psicologia: Saúde Mental e Seg. Pública, B Hte., 6, 35-50, jan./jun. 2017.

RC: 93449

Disponível em: https://www.nucleodoconhecimento.com.br/psicologia/psicologia-epolicia 
OLIVEIRA, Thamires Sousa; FAIMAN; Carla Júlia Segre. Ser policial militar: reflexos na vida pessoal e nos relacionamentos. Revista Psicologia: Organizações e Trabalho, 19(2), abr-jun 2019.

OLIVEIRA, Katya Luciane, SANTOS, Luana Minharo. A percepção da saúde mental em policiais militares da força tática e de rua. Sociologias, Porto Alegre, ano 12, no 25, set./dez. 2010, p. 224-250 Disponível em: < https://www.scielo.br/j/soc/a/kRWWYHPFpWbvhGmMdbjtqcp/?format=pdf\&lang=pt> Acesso em: 27 de jun.2021.

PUTTI, Alexandre. Suicídio de policiais é um problema grave no Brasil, aponta estudo. Disponível em: <https://www.cartacapital.com.br/sociedade/suicidio-depoliciais-e-um-problema-grave-no-brasil-aponta-estudo/> Acesso em: 15 de jun. 2021.

RESENDE, Marcelo Augusto; CAVAZZA, Belinda Inês Sabino. O POLICIAL MILITAR E A VIOLÊNCIA: de agente a vítima. Revista de Psicologia: Saúde Mental e Segurança Pública, Belo Horizonte, 2, 51-56, jan./dez. 2002

SANTANA, Sérgio Lopes; SABINO, Alini Danieli Viana. Estresse Policial Militar: efeitos psicossociais. Disponível em: < http://www.aems.edu.br/conexao/edicaoanterior/Sumario/2012/downloads/2012/hum anas/ESTRESSE\%20POLICIAL\%20MILITAR\%20EFEITOS\%20PSICOSSOCIAIS.pd f> Acesso em 19 nov. 2020.

SILVA, E. A influência do estresse na vida profissional do policial militar do Estado de

Goiás. Trabalho de Conclusão de Curso (Especialização) - Academia de Policia Militar, Goiânia, 2007. Disponível em:< https://bdm.unb.br/bitstream/10483/2993/1/2011_JanaryBarbosaDias.pdf> acesso em: 08 jun. 2021.

RC: 93449

Disponível em: https://www.nucleodoconhecimento.com.br/psicologia/psicologia-epolicia 
SOUZA, Edinilsa Ramos de et al. Fatores associados ao sofrimento psíquico de policiais militares da cidade do Rio de Janeiro, Brasil. Cad. Saúde Pública, Rio de Janeiro , v. 28, n. 7, p. 1297-1311, July 2012. Disponível em: $<$ http://www.scielo.br/scielo.php?script=sci_arttext\&pid=S0102311X2012000700008 \&lng=en\&nrm=iso $>$. Acesso em: 16 Nov. 2020.

SOUZA, Edinilsa Ramos; MINAYO, Maria Cecília de Souza; PIRES, Thiago de Oliveira. Fatores associados ao sofrimento psíquico de policiais militares da cidade do Rio de Janeiro, Brasil. Artigo • Cad. Saúde Pública 28 (7) • Jul 2012

SOUZA, Katarinne Soares Rosa, MACÊDO, Shirley. Experiência de ser esposa de policial militar: um estudo fenomenológico. Revista da Abordagem Gestáltica | Vol. XXVI-3 (2020).

SOUSA, Raphaela Campos. Condições emocionais dos Policiais Militares do interior de Minas Gerais. Dissertação (Mestrado em Psicologia) - Universidade Federal do Triangulo Mineiro, Uberaba, MG, 2018.

SPULDARO, Josiane Carine; NESI; Tainara Cristina. A ocorrência de estresse em policiais militares do $20^{\circ}$ batalhão de polícia militar de concórdia - Santa Catarina. Saúde Meio Ambient. v. 2, n. 1, p. 16-32, jan./jun. 2013.

Enviado: Julho, 2021.

Aprovado: Agosto, 2021.

RC: 93449

Disponível em: https://www.nucleodoconhecimento.com.br/psicologia/psicologia-epolicia 